\title{
Effects of an Airway Clearance Device on Inflammation, Bacteriology, and Mucus Transport in Bronchiectasis
}

\author{
Joana Tambascio PT PhD, Hugo Celso Dutra de Souza PT PhD, Roberto Martinez MD PhD, \\ José Antônio Baddini-Martinez MD PhD, Peter John Barnes MD PhD, and \\ Ada Clarice Gastaldi PT PhD
}

\begin{abstract}
BACKGROUND: Bronchiectasis is characterized by abnormal and permanent dilation of the bronchi, caused by the perpetuation of inflammation and impairment of mucociliary clearance. Physiotherapy techniques can help to decrease the retention of respiratory secretions. The flutter valve combines high-frequency oscillation and positive expiratory pressure to facilitate the removal of secretions. We evaluated the effects of the flutter valve on sputum inflammation, microbiology, and transport of respiratory secretions in patients with bronchiectasis. METHODS: Seventeen participants underwent sessions with flutter or control (flutter-sham), for $30 \mathrm{~min} / \mathrm{d}$, in a randomized crossover study, with 4 weeks with one of the therapies, a 2-week wash-out period, and then another 4 weeks with the other modality. Secretion samples were collected every week throughout the protocol and were assessed for the mucociliary transport, displacement in a simulated cough machine, contact angle, and cell cytology with percentage of neutrophil count, eosinophils, and macrophages, and the microbiology was assessed by the number of colony-forming units. RESULTS: Treatment with flutter resulted in greater displacement in a simulated cough machine and smaller contact angle, comparing the results between the first week $\left(9.94 \pm 3.12 \mathrm{~cm}\right.$ and $26.5 \pm 3.21^{\circ}$, respectively) and fourth week of treatment $\left(13.96 \pm 5.76 \mathrm{~cm}\right.$ and $22.76 \pm 3.64^{\circ}$, respectively) and was associated with a decrease in the total number of inflammatory cells. CONCLUSIONS: The use of a flutter valve for $30 \mathrm{~min} / \mathrm{d}$ for at least 4 weeks is enough to change physical properties and improve mucus transport by coughing and can contribute to the reduction of the total number of inflammatory cells of the respiratory secretions of subjects with bronchiectasis. (ClinicalTrials.gov registration NCT01209546.) Key words: bronchiectasis; sputum; respiratory physiotherapy; тисоciliary transport; inflammation; infection. [Respir Care 2017;62(8):1067-1074. (C) 2017 Daedalus Enterprises]
\end{abstract}

\section{Introduction}

Bronchiectasis is a condition that is pathologically characterized by the abnormal and permanent dilation of one or more bronchi with chronic cough, expectoration of purulent sputum, and dyspnea as the main symptoms. ${ }^{1-3}$ Ini-

Drs Tambascio, de Souza, and Gastaldi are affiliated with the Department of Physiotherapy, and Drs Martinez and Baddini-Martinez are affiliated with the Department of Internal Medicine, Ribeirão Preto Medical School, University of São Paulo, São Paulo, Brazil. Dr Barnes is affiliated with the Faculty of Medicine, National Heart and Lung Institute, Imperial College London, London, United Kingdom.

This work was supported by the São Paulo Research FoundationFAPESP. The authors have disclosed no conflicts of interest. tially, this dilation is related to a destructive process on bronchial walls, caused mainly by bacterial infection and continuous inflammation; this results in the destruction of the epithelial lining and of the muscular and elastic components of the bronchial walls. ${ }^{4-6}$ Destruction of the epithelium causes decreased mucociliary transport, which is the primary defense mechanism of the lower airways. Additionally, there is hypertrophy of mucus secretory cells and alteration of the composition of the respiratory mucus,

Correspondence: Ada Clarice Gastaldi PT PhD, Avenida dos Bandeirantes S/N, Campus Universitário, Ribeirão Preto-SP, 14049-900 São Paulo, Brazil. E-mail: ada@fmrp.usp.br.

DOI: $10.4187 /$ respcare. 05214 
which further impairs its clearance..$^{2,4,7-9}$ Thus, mucus hypersecretion in patients with bronchiectasis is a permanent situation, with periods of exacerbation, which are associated with increased secretion produced. ${ }^{10}$

In addition to pharmacologic and/or surgical treatment, respiratory therapy is also indicated for patients with bronchiectasis, because patients have difficulty in the transport and elimination of mucus. Therefore, they may benefit from physiotherapy and its various techniques. ${ }^{11}$ The flutter valve is a physical therapy alternative device for these patients because it combines 2 important secretion removal techniques: positive expiratory pressure and high-frequency oscillation. Positive expiratory pressure assists in the removal of secretions by increasing alveolar pressure as a result of expiration against resistance, favoring inflation of collapsed alveoli by collateral ventilation and increased expiratory flow. However, the main benefit of the flutter is attributed to high-frequency oscillation, possibly because of the thixotropic effect, a property of mucus that results in reduced viscosity when submitted to oscillation. This change in the mucus properties may result in different macroscopic aspects and transport by ciliary system or air flow. ${ }^{12}$

In subjects with bronchiectasis, previous research has studied the effectiveness of the flutter in relation to expectorated secretion volume, ${ }^{13}$ mucociliary transport by the frog palate method, displacement in the simulated cough machine, contact angle, and respiratory secretion viscosity. ${ }^{10,14,15}$

Tambascio et al ${ }^{12}$ demonstrated an improvement in respiratory secretion transport after exercises with Flutter VRP1 in subjects with bronchiectasis. It has been speculated that this increase in the displacement by coughing and a reduction in the contact angle could be attributed to thixotropic flow, ${ }^{16,17}$ and this effect had been demonstrated by App et $\mathrm{al}^{17}$ and Ramos et al ${ }^{14}$ in subjects with bronchiectasis and cystic fibrosis, respectively.

Because hypersecretion and/or mucus stasis contributes to the perpetuation of the inflammatory process, ${ }^{3,18}$ we hypothesized that favoring the removal of secretions with the flutter valve technique, which is capable of increasing the volume of sputum, could also modify the inflammatory and microbiological profile of respiratory secretions. Thus, the aim of the study was to evaluate the effects of the flutter device on the inflammatory and microbiological mucus profile, as well as transport rates of respiratory secretions, in subjects with non-cystic fibrosis bronchiectasis.

\section{Methods}

\section{Study Subjects}

We evaluated 65 clinically stable subjects with noncystic fibrosis bronchiectasis, as defined by medical his-

\section{QUICK LOOK}

\section{Current knowledge}

The flutter valve is an airway clearance device for patients with bronchiectasis. Previous research has studied the effectiveness of the device in different aspects. However, no study has evaluated the effectiveness of the flutter device on the inflammatory and microbiological mucus profile.

\section{What this paper contributes to our knowledge}

The main contribution of our results is the therapeutic potential of respiratory therapy in patients with bronchiectasis, which has not been described for physiotherapy techniques. The flutter was associated with improvements in the inflammatory process of respiratory secretions in patients with bronchiectasis.

tory and clinical examination and confirmed by computed tomography scanning, from the out-patient pneumology clinic in the university hospital. Patients who had no amount $>0.5 \mathrm{~mL}$ of respiratory secretion or who had developed any type of respiratory infection in the 4 weeks before baseline or during the protocol were excluded from the study. This study was registered in the Protocol Registration System, ClinicalTrials.gov, and the participating subjects were informed of all stages of the study and signed a written consent form approved by the local ethics committee (approval 6007/2007).

\section{Protocol}

Initially, patients with the diagnosis of non-cystic fibrosis bronchiectasis confirmed by computed tomography scanning were evaluated, and those who agreed to participate in the study were randomized through the draw for 2 groups: the control group or the flutter group. Before the beginning of the study, subjects were randomized into the flutter group or the control group. The flutter equipment was used without modifications in the flutter group, whereas the control group used the flutter device without the stainless steel ball inside. The exercises were performed in a sitting position; subjects were instructed to perform long breathing during the treatment.

Subjects in the control group or the flutter group carried out exercise sessions with the flutter device (Flutter VRP1, VarioRaw S.A., Switzerland) for $30 \mathrm{~min}$ daily in a randomized crossover study. They were subject to 4 weeks of treatment with one of the therapies ${ }^{11,17,19}$ followed by a 2-week wash-out period and then by 4 weeks with the other modality (Fig. 1). 


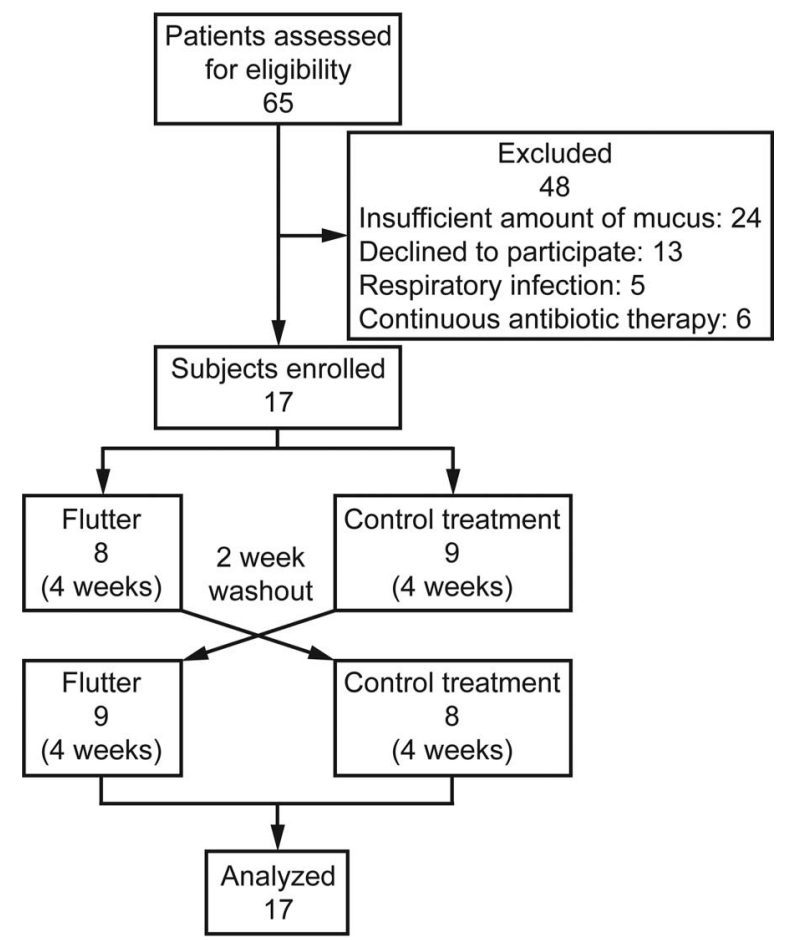

Fig. 1. Flow chart.

In the first and fourth weeks of treatment with each modality, the subjects' respiratory secretions and sputum were collected after voluntary coughing supervised by the researcher for the following assessments: adhesiveness, purulence, mucociliary transport, displacement in the simulated cough machine, contact angle measurement, cytological analysis, and microbiological evaluation.

Adhesiveness. Immediately after the secretions had been separated from the saliva, the mucus was evaluated in terms of its "pourability" (adhesiveness), being graded on a scale ranging from 1 (adheres closely to the container) to 4 (pours easily). The samples that received adhesiveness grades of 1 or 2 were classified as adhesive, whereas those that received adhesiveness grades of 3 or 4 were classified as not adhesive. ${ }^{20}$

Purulence. Immediately after evaluation of adhesion, the secretions were assessed for purulence while assigning a denomination (mucoid, mucopurulent, or purulent) according to the visual scale proposed by Murray et al. ${ }^{21}$ The strains with mucoid ratings were classified as mucoid, and those that were mucopurulent or purulent were classified as purulent. ${ }^{22}$

Mucociliary Transport. Frogs (Rana catesbiana) had their palates removed following decapitation and were maintained at $4^{\circ} \mathrm{C}$ for $48 \mathrm{~h}$ to collect the mucus. Small amounts of subject mucus were removed from a plastic tube and were submerged in ether to remove excess Vaseline and then deposited on the palate. The sample displacement was observed using a stereomicroscope with an $8 \times$ magnification lens (Stemi 1000, Carl Zeiss, Göttingen, Germany), and the transport time was recorded with the use of a chronometer (8904, Herweg, Santa Catarina, Brazil). ${ }^{12,22}$ The results were expressed as relative transport velocity compared with the average of 5 experimental mucus transport velocity measurements for the frog (average of the summed velocity of the initial and final frog speeds for the experimental mucus evaluation).

Displacement in the Simulated Cough Machine. Analysis of the cough machine mucus transport was completed according to the model described by King et al ${ }^{16}$ and adopted by the Heart Institute Precision Institute (InCor) (São Paulo, Brazil). The model was composed of a pressure source, a solenoid valve, and a simple scheme of airways, represented by a dry acrylic cylinder measuring $30 \mathrm{~cm}$ in length and $4 \mathrm{~mm}$ in internal diameter, with the three elements connected in a series. When the cough simulator machine was activated, the timing device controlled opening of the solenoid for $1 \mathrm{~s}$, allowing the exit of air at $4.2 \mathrm{~kg} / \mathrm{cm}^{2}$ of pressure, thus moving the secretion sample. ${ }^{12,22}$ Each mucus sample was tested 5 times, and the average of these 5 displacements was used.

Contact Angle Measurement. The angle, in degrees, formed between the mucus and the glass surface was considered the contact angle and was measured using a goniometer with a $20 \times$ magnification lens. The glass surface used for these analyses was treated with sulfochromic acid to remove any electrical charge. The sample was evaluated 5 times, and the average of these measurements was used. ${ }^{12,22}$

Cytological Analysis. The respiratory secretions were homogenized with dithiothreitol at $0.1 \%$ (Life Technologies Inc., Grand Island, New York), mixed with a model TE053 Dubnoff shaker (Tecnal, Piracicaba, Brazil), centrifuged (Allegra 21R centrifuge, Beckman, Palo Alto, California), and stained by trypan blue. For total count of cells and cell viability analysis, $10 \mu \mathrm{l}$ of this solution was placed in a Neubauer chamber (Fein-Optik, Blackenburg, Germany) and displayed in the optical microscope. At least 200 non-squamous cells were counted to obtain the cell composition, expressed as a percentage of macrophages, eosinophils, lymphocytes, and neutrophils. The differential cell count was performed by an experienced technician from the pulmonology laboratory of the institution, who did not have access to subject data or the requests for interventions, and it was expressed as a percentage of the total number of cells and in terms of macrophages, eosinophils, lymphocytes, and neutrophils..$^{23}$ 
Effects of an Airway Clearance Device

Table 1. Data Concerning Age, Sex, Etiology of Bronchiectasis, $\mathrm{FVC} \%, \mathrm{FEV}_{1} \%$, and $\mathrm{FEV}_{1} / \mathrm{FVC}$ of Each Participant

\begin{tabular}{|c|c|c|c|c|c|c|}
\hline Subject number & Age (y) & Sex & Etiology & FVC (\% predicted $)$ & $\mathrm{FEV}_{1}(\%$ predicted $)$ & $\mathrm{FEV}_{1} / \mathrm{FVC}$ \\
\hline 1 & 80 & Female & Pneumonia of repetition & 91 & 58 & 0.48 \\
\hline 2 & 65 & Male & Sequel to tuberculosis & 40 & 24 & 0.48 \\
\hline 3 & 63 & Female & Sequel to tuberculosis & 57 & 41 & 0.60 \\
\hline 4 & 68 & Male & Pneumonia of repetition & 79 & 29 & 0.28 \\
\hline 5 & 50 & Male & Pneumonia of repetition & 80 & 38 & 0.38 \\
\hline 6 & 57 & Female & Idiopathic & 71 & 67 & 0.78 \\
\hline 7 & 36 & Male & Idiopathic & 62 & 25 & 0.47 \\
\hline 8 & 55 & Female & Pneumonia of repetition & 61 & 65 & 0.88 \\
\hline 9 & 64 & Male & Pneumonia of repetition & 40 & 19 & 0.37 \\
\hline 10 & 30 & Female & Pneumonia of repetition & 71 & 39 & 0.48 \\
\hline 11 & 61 & Female & Pneumonia of repetition & 58 & 44 & 0.63 \\
\hline 12 & 42 & Female & Pneumonia of repetition & 72 & 49 & 0.47 \\
\hline 13 & 38 & Female & Pneumonia of repetition & 73 & 65 & 0.75 \\
\hline 14 & 64 & Male & Sequel to tuberculosis & 70 & 25 & 0.56 \\
\hline 15 & 41 & Male & Pneumonia of repetition & 65 & 27 & 0.60 \\
\hline 16 & 68 & Female & Pneumonia of repetition & 70 & 30 & 0.30 \\
\hline 17 & 50 & Female & Pneumonia of repetition & 103 & 76 & 0.63 \\
\hline
\end{tabular}

Microbiological Evaluation. The secretions were homogenized, diluted in a $0.9 \%$ saline solution, and deposited in blood agar plates, which were subsequently spread with a bacteriological loop. The plates were then incubated in an oven at $35^{\circ} \mathrm{C}$ for $24 \mathrm{~h}$ and held the visual reading of bacterial growth in colony-forming units. Later, we calculated the concentration of colony-forming units/g of respiratory secretion based on the highest-dilution plate on which there was microbial growth. The predominant bacteria isolated by this method were identified in relation to the genus and species by microbiological automation system 1 Vitek (Biomerieux). The analyses were performed by an experienced technician from the microbiology laboratory of the institution who did not have access to subject data or the requests for interventions. The main bacteria identified were Pseudomonas aeruginosa, Streptococcus mitis, Streptococcus pneumoniae, Streptococcus salivarius, Streptococcus sanguinis, Moraxella catarrhalis, and Sphingomonas paucimobilis.

\section{Statistical Analysis}

The sample calculation was based on the simulated cough machine results from a previous study ${ }^{12}$ with an SD value of $3.4 \mathrm{~cm}$, an effect to be detected of 3.84 , a power of $90 \%$, and an $\alpha$ of $5 \%$ and resulted in 11 subjects. This study was conducted with 17 subjects. A possible sequential effect was initially evaluated using unpaired tests. Because there was no effect on sequential treatment of patients, the results were analyzed by comparing the differences between the treatments in the control group and flutter group. The data were compared using paired tests, the $t$ test or the Wilcoxon signed-rank test, depending on the evaluation of the distribution, and were presented as means and SD. For cytology and microbiology variables, the size of the effect was also calculated using Cohen's kappa coefficient, along with minimum important difference and Fisher exact test. ${ }^{24}$ The statistical analysis was performed with GraphPad Prism 6 with the significance level set at $5 \%$.

\section{Results}

In the case of a long protocol of 10 weeks, 48 patients were excluded, as shown in Figure 1. Of the 17 subjects with non-cystic fibrosis bronchiectasis who were included in the study, 10 were female and 7 were male, with a mean age of $54.8 \pm 13.7$ y. 14 subjects had purulent sputum by macroscopic appearance, and 3 had mucopurulent sputum, whereas all samples evaluated were adhesive. Table 1 contains data concerning the age, sex, etiology of bronchiectasis, $\mathrm{FVC}, \mathrm{FEV}_{1}, \mathrm{FEV}_{1} / \mathrm{FVC}$, and randomized group of each participant.

Only one of these subjects showed a negative initial culture. Of those who had a positive culture, 11 had P. aeruginosa; 5 had S. mitis; 3 had S. pneumoniae, 2 had S. salivarius, and one each had S. sanguinis, M. catarrhalis, and S. paucimobilis.

\section{Mucociliary Transport}

There was no significant difference in the values for mucociliary transport when evaluating the transport using the frog palate model between the pretreatment and posttreatment weeks in the flutter group $(0.85 \pm 0.25$ and $0.89 \pm 0.23$, respectively) or the control group $(0.76 \pm 0.21$ and $0.80 \pm 0.31$, respectively). 


\section{Displacement in the Simulated Cough Machine}

There was a statistically different increase in the values of displacement in a simulated cough machine between the pretreatment and post-treatment weeks in the flutter group (9.94 \pm 3.12 and $13.96 \pm 5.76 \mathrm{~cm}$, respectively), which was not obtained in the control group $(9.95 \pm 5.05$ and $9.85 \pm 3.9 \mathrm{~cm}$, respectively) (Fig. 2).
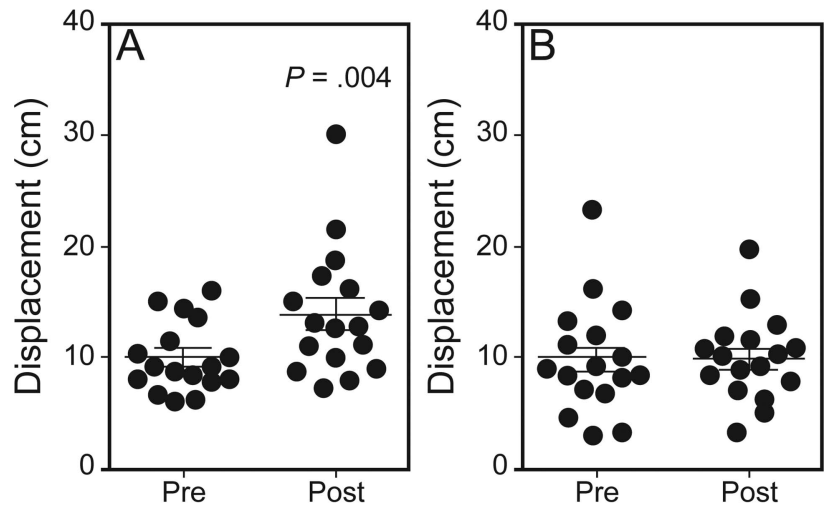

Fig. 2. Displacement in a simulated cough machine before and after treatment for the flutter (A) and control (B) groups. Center lines denote the average, and whiskers show \pm SD.
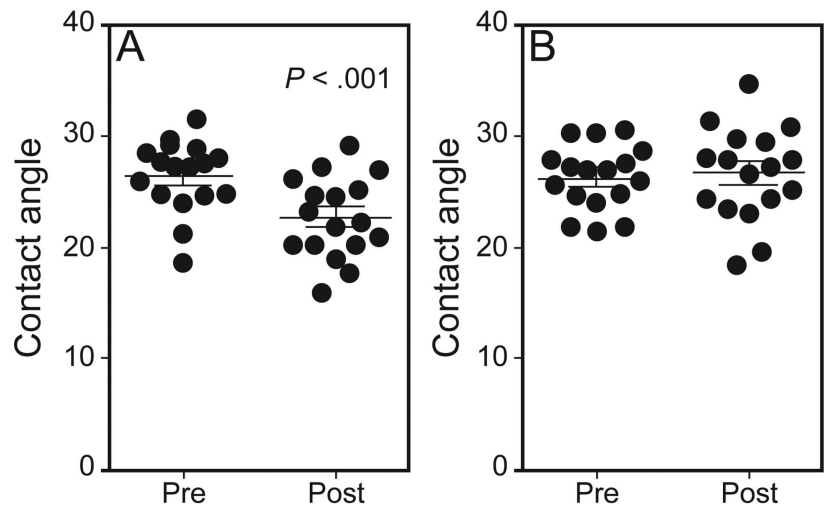

Fig. 3. Contact angles in flutter (A) and control (B) groups, before and after treatment. Center lines denote the average, and whiskers show \pm SD.

\section{Contact Angle}

There was a statistically different decrease in the values of the contact angle between the pretreatment and posttreatment weeks in the flutter group $(26.5 \pm 3.21$ and $22.76 \pm 3.64^{\circ}$, respectively), which was not seen in the control group $\left(26.34 \pm 2.91\right.$ and $26.76 \pm 4.18^{\circ}$, respectively) (Fig. 3).

\section{Sputum Cytology}

There was no significant difference in the values for the evaluated variables (total number of cells, eosinophils, neutrophils, macrophages, and lymphocytes), although a decrease in the values between the pretreatment and posttreatment weeks was verified in both the flutter group and the control group. Table 2 shows the values of the variables before and after treatment, along with the effect of the treatment $(95 \% \mathrm{CI})$.

When the size of the effect on the flutter group was evaluated, there was a statistically significant decrease in the total number of inflammatory cells, which was not seen in the control group. Figure 4 shows the frequency of subjects in the flutter group and the control group who had a decrease greater than the minimum important difference or an increase or decrease less than the minimum important difference in the total number of inflammatory cells. (Fig. 4).

\section{Microbiology}

There was no statistical difference in the number of colony-forming units/g of secretion, although a decrease in the values between the pretreatment and post-treatment weeks was verified in both the flutter group and the control group. There was no significant difference in the total number of colony-forming units/g in the pre- and posttreatment periods.

Table 2. Values of Inflammatory Cell Count Variables Evaluated Before and After Treatments and the Treatment Effect

\begin{tabular}{|c|c|c|c|c|c|}
\hline \multirow{2}{*}{$\begin{array}{l}\text { Values of inflammatory } \\
\text { cell counts }\end{array}$} & \multicolumn{2}{|r|}{ Flutter } & \multicolumn{2}{|r|}{ Control } & \multirow{2}{*}{$\begin{array}{c}\text { Treatment } \\
\text { Effect }(95 \% \mathrm{CI})\end{array}$} \\
\hline & Pretreatment & After 4 Weeks of Treatment & Pretreatment & After 4 Weeks of Treatment & \\
\hline Total number $\left(10^{6}\right)$ & $15.17 \pm 14.32$ & $7.17 \pm 9.84$ & $16.78 \pm 15.68$ & $9.08 \pm 9.40$ & -8.87 to 9.68 \\
\hline Eos $\%$ & $2.26 \pm 2.82$ & $1.62 \pm 1.78$ & $3.41 \pm 7.49$ & $3.03 \pm 4.09$ & -7.97 to 2.38 \\
\hline $\mathrm{Neu} \%$ & $83.88 \pm 9.23$ & $81.18 \pm 21.91$ & $83.21 \pm 11.88$ & $73.74 \pm 30.24$ & -11.22 to 24.74 \\
\hline $\mathrm{Mac} \%$ & $6.82 \pm 6.05$ & $5.29 \pm 5.13$ & $7.35 \pm 9.66$ & $5.74 \pm 5.88$ & -4.52 to 4.7 \\
\hline Lym\% & $6.32 \pm 5.82$ & $5.68 \pm 4.25$ & $5.88 \pm 3.59$ & $5.32 \pm 5.33$ & -6.17 to 5.99 \\
\hline $\begin{array}{l}\text { Eos } \%=\text { eosinophils } \\
\text { Neu } \%=\text { neutrophils } \\
\text { Mac\% }=\text { macrophages } \\
\text { Lym\% }=\text { lymphocytes }\end{array}$ & & & & & \\
\hline
\end{tabular}



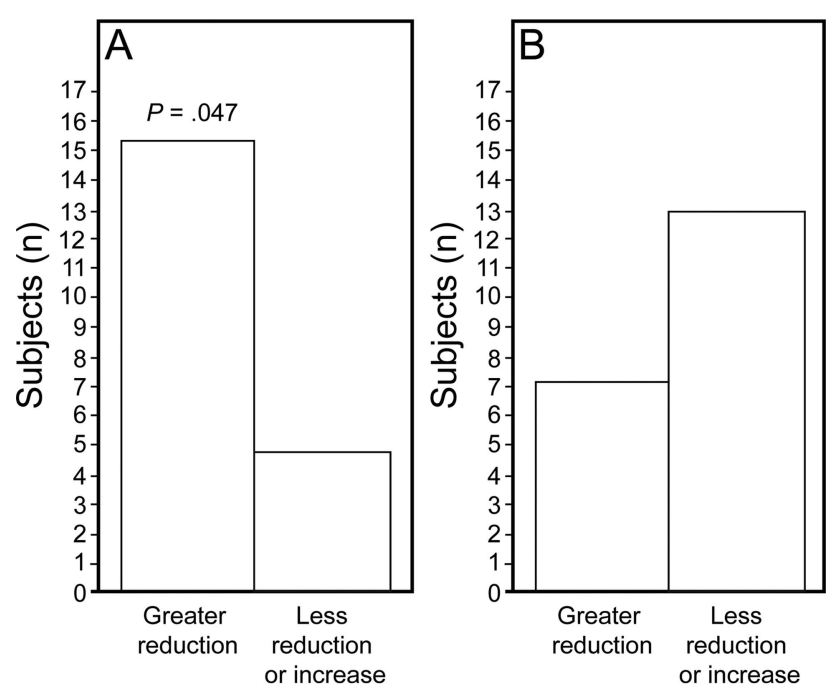

Fig. 4. Flutter (A) and control (B) subjects who obtained total inflammatory cell count reductions greater than the minimal important difference versus those who obtained either a lesser reduction than the minimal important difference or an increase in total inflammatory cell count.

\section{Discussion}

In this study, mucociliary transport, displacement in the simulated cough machine, contact angle, the inflammatory profile, and bacterial counting of respiratory secretions were evaluated in subjects with bronchiectasis who underwent treatment with the flutter device compared with a control device. At the end of the fourth week of treatment in the samples subjected to treatment with the flutter device, the results showed an increase in displacement in the simulated cough machine and a decrease in contact angle, and this improvement in transport properties is related with changes in the physical and/or surface mucus properties. Additionally, the flutter treatment induced a decrease in the total number of sputum inflammatory cells that could be related to a decrease in the mucus stasis.

It is important to note that these improvements in the transport properties are similar to those in our previous study, ${ }^{12}$ but we found an additional beneficial effect in the inflammatory profile demonstrated by a decrease in the total number of inflammatory cells after use of the flutter valve compared with a control or sham group. We speculate that changes in the properties of respiratory secretions induced by the device, such as the increase in displacement in the simulated cough machine, facilitating transport and elimination and decreasing the stasis of the mucus, could also contribute to a decrease in the inflammation.

Spirometry values presented in the results aimed to characterize the patients population. It is worth mentioning that the initial protocol found no changes in pulmonary function values after daily use of the device for the 4 weeks.
Our findings are in agreement with previous studies with this device, which compared the flutter device with autogenic drainage and positive expiratory pressure. The studies reported improvement in the transport indexes of respiratory secretions after 4 weeks in subjects with cystic fibrosis and bronchiectasis. ${ }^{11,12,17}$ Besides improvement of transport indexes or rheological properties, ${ }^{11,14,15}$ previous studies in subjects with bronchiectasis have also found improvements in expectorated volume, ${ }^{11,25,26}$ lung function, ${ }^{11,25-27}$ and acceptability of the technique. ${ }^{28}$

We also found that there was a reduction in the variables in sputum bacterial colony counts in both the flutter valve and control groups. This effect in the controls may be related to the improved health care provided to the subjects. Although the device was used without the steel ball inside, subjects did undergo 30 min of daily breathing exercises without resistance or oscillation, always followed by coughing. The lack of significant results with differential inflammatory cells and microbiology may be related to the sample calculation, which was performed with the displacement of respiratory secretions as the evaluated variable and may have underestimated the variability in cytology and microbiology measurements.

The pathophysiology of bronchiectasis is related to the continuous inflammatory process, ${ }^{3}$ and neutrophils are the predominant cells in the respiratory secretions of patients with stable bronchiectasis. ${ }^{29,30}$ As in other studies, we have demonstrated a high percentage $(>60 \%)$ of neutrophils in sputum $^{3,23,31}$ and observed a reduction in these cells following treatment of $3 \%$ in the flutter group and $9 \%$ in controls.

The sputum of patients with bronchiectasis may vary from mucoid to purulent, and this is related to infections caused by bacteria such as Haemophilus influenzae, ${ }^{25,32}$ $S$. pneumoniae, $M$. catarrhalis, and $P$. aeruginosa. ${ }^{33}$ In our study, all samples obtained were evaluated and classified as purulent and adhesive. This resulted in a more homogeneous group of samples, excluding the interference of the macroscopic aspect and the adhesiveness of the analyzed variables.

Assuming that germs S. mitis, S. salivarius, and S. sanguinis are colonizers of the oral cavity and therefore are correlated with contamination of respiratory secretion, our findings are consistent with previous studies, which concluded that the organisms most frequently found in patients with bronchiectasis are P. aeruginosa, M. catarrhalis, and $S$. pneumoniae. ${ }^{3,30,34-36}$ Colonization by $P$. aeruginosa is associated with a more rapid decline in lung function, morbidity, and mortality. $3,37,38$ We found a reduction in colonyforming units of $53 \%$ in the flutter group and $48 \%$ in the control group, although these differences were not significant.

Nicolini et al $^{39}$ compared the technique of high-frequency oscillation with the use of the Vest airway clearance sys- 
tem in subjects with bronchiectasis. They found that in addition to improvement in the parameters of pulmonary function and dyspnea, high-frequency thoracic oscillation was also capable of reducing systemic inflammation (decrease in C-reactive protein) and the percentage of neutrophils after $15 \mathrm{~d}$ of treatment lasting $30 \mathrm{~min} / \mathrm{session}$, twice a day. ${ }^{39}$ The main contribution of our results and those of Nicolini et $\mathrm{al}^{39}$ is the therapeutic potential of respiratory therapy in patients with bronchiectasis, because both studies demonstrate the possibility of bringing about improvements in the inflammatory process of respiratory secretions as well as systemic inflammation in patients with bronchiectasis.

There are limitations to this work. The assessment of the degree of inflammation in the airways could have been complemented with the use of systemic inflammatory markers. In addition, the quality of life and sputum amount quantity could have been evaluated.

In addition, there were many patients excluded from the protocol. It is important to note that much of this exclusion did not happen during the protocol but previously. Most exclusion did not provide enough respiratory secretion to the different evaluations. However, the sample size is in accordance with the sample calculation performed previously. The sample calculation was conducted with a power of $90 \%$ and $\alpha$ of $5 \%$, which resulted in a total of 11 subjects.

\section{Conclusions}

The use of the flutter device for 30 min daily for at least 4 weeks in subjects with bronchiectasis was able to improve the physical properties of respiratory secretions and enhance transport by coughing and led to a reduction in the total number of inflammatory cells in the respiratory secretions.

\section{REFERENCES}

1. Fahy JV, Schuster A, Ueki I, Boushey HA, Nadel JA. Mucus hypersecretion in bronchiectasis. The role of neutrophil proteases. Am Rev Respir Dis 1992;146(6):1430-1433.

2. Moreira JS, Porto NS, Camargo JJP, Felicetti JC, Cardoso PFG, Moreira ALS, et al. Bronquiectasias: aspectos diagnósticos e terapêuticos: estudo de 170 pacientes. J Pneumol 2003;29(5):258-263.

3. Bergin DA, Hurley K, Mehta A, Cox S, Ryan D, O'Neill SJ, et al. Airway inflammatory markers in individuals with cystic fibrosis and non-cystic fibrosis bronchiectasis. J Inflamm Res 2013;6:1-11.

4. Jamnik S, Lopes SI, Muniz MMT, Ande SL, Souza de OliveiraJúnior I. Características clínicas, gasométricas y espirométricas em pacientes portadores de bronquiectasias com saturación superior e inferior a 91\% de oxigênio. Neumología Cirugía Tórax 2002;61(1): 5-9.

5. Karadag B, Karakoc F, Ersu R, Kut A, Bakac S, Dagli E. Non-cysticfibrosis bronchiectasis in children: a persisting problem in developing countries. Respiration 2005;72(3):233-238.
6. Goeminne P, Dupont L. Non-cystic fibrosis bronchiectasis: diagnosis and management in 21st century. Postgrad Med J 2010;86(1018): 493-501.

7. Silva JR, Jones JA, Cole PJ, Poulter LW. The immunological component of the cellular inflammatory infiltrate in bronchiectasis. Tho$\operatorname{rax} 1989 ; 44(8): 668-673$.

8. Richman-Eisenstat JB, Jorens PG, Hébert CA, Ueki I, Nadel JA. Interleukin-8: an important chemoattractant in sputum of patients with chronic inflammatory airway diseases. Am J Physiol 1993;264: L413-L418.

9. Chalmers JD, Hill AT. Mechanisms of immune dysfunction and bacterial persistence in non-cystic fibrosis bronchiectasis. Mol Immunol 2013;55(1):27-34.

10. Valente A, Gastaldi A, Cravo S, Afonso J, Sologuren M, Guimarães $\mathrm{R}$. The effect of two techniques on the characteristics and transport of sputum in patients with bronchiectasis: a pilot study. Physiotherapy 2004;90(3):158-164.

11. Thompson CS, Harrison S, Ashley J, Day K, Smith DL. Randomised crossover study of the Flutter device and the active cycle of breathing technique in non-cystic fibrosis bronchiectasis. Thorax 2002; 57(5):446-448

12. Tambascio J, de Souza LT, Lisboa RM, Passarelli Rde C, de Souza HC, Gastaldi AC. The influence of Flutter(R)VRP1 components on mucus transport of patients with bronchiectasis. Respir Med 2011; 105(9):1316-1321.

13. Oliveira Antunes LC, Carvalho SMF, Borges FD, Assis VLGN, Godoy I. Comparação da eficácia da fisioterapia respiratória convencional com o Flutter VRP1 em pacientes com bronquiectasia. Revista Salusvita 2001;20(1):11-21.

14. Ramos EMC, Ramos D, Iyomasa DM, Moreira GL, Melegati KCT, Vanderlei LCM, et al. Influência da técnica de pressão expiratória positiva oscilante utilizando pressões expiratórias pré-determinadas na viscosidade e na transportabilidade do escarro em pacientes com bronquiectasia. J Bras Pneumol 2009;35(12):1190-1197.

15. Pires Neto R, Ramos E, Ramos D. Transportabilidade e viscoelasticidade do muco bronquico, de um paciente com bronquiectasia, expectorado apos a tapotagem eo aparelho Flutter-VRP1: estudo de caso. Braz J Phys Ther 2004;8(2):165-168.

16. King M, Brock G, Lundell C. Clearance of mucus by simulated cough. J Appl Physiol 1985;58(6):1776-1782.

17. App EM, Kieselmann R, Reinhardt D, Lindemann H, Dasgupta B, King M, Brand P. Sputum rheology changes in cystic fibrosis lung disease following two different types of physiotherapy: flutter vs autogenic drainage. Chest 1998;114(1):171-177.

18. Tegner H, Ohlsson K, Toremalm NG, von Mecklenburg C. Effect of human leukocyte enzymes on tracheal mucosa and its mucociliary activity. Rhinology 1979;17(3):199-206.

19. van Winden CM, Visser A, Hop W, Sterk PJ, Beckers S, de Jongste JC. Effects of flutter and PEP mask physiotherapy on symptoms and lung function in children with cystic fibrosis. Eur Respir J 1998; 12(1):143-147.

20. Lopez-Vidriero MT, Charman J, Keal E, De Silva DJ, Reid L. Sputum viscosity: correlation with chemical and clinical features in chronic bronchitis. Thorax 1973;28(4):401-408.

21. Murray MP, Pentland JL, Turnbull K, MacQuarrie S, Hill AT. Sputum colour: a useful clinical tool in non-cystic fibrosis bronchiectasis. Eur Respir J 2009;34(2):361-364.

22. Tambascio J, Lisboa RM, Passarelli Rde C, Martinez JA, Gastaldi AC. Adhesiveness and purulence of respiratory secretions: implications for mucociliary transport in patients with bronchiectasis. J Bras Pneumol 2010;36(5):545-53.

23. Pereira AC, Kokron CM, Romagnolo BM, Yagi CS, Saldiva PH, Lorenzi Filho G, Negri EM. Analysis of the sputum and inflammatory altera- 


\section{Effects of an Airway Clearance Device}

tions of the airways in patients with common variable immunodeficiency and bronchiectasis. Clinics 2009;64(12):1155-1160.

24. Armijo-Olivo S, Warren S, Fuentes J, Magee DJ. Clinical relevance vs. statistical significance: using neck outcomes in patients with temporomandibular disorders as an example. Man Ther 2011;16(6): 563-572.

25. Chicayban LM, Zin WA, Guimarães FS. Can the Flutter Valve improve respiratory mechanics and sputum production in mechanically ventilated patients? A randomized crossover trial. Heart Lung 2011; 40(6):545-53.

26. Guimarães FS, Moço VJ, Menezes SL, Dias CM, Salles RE, Lopes AJ. Effects of ELTGOL and Flutter VRP1(R) on the dynamic and static pulmonary volumes and on the secretion clearance of patients with bronchiectasis. Rev Bras Fisioter 2012;16(2):108-113.

27. Figueiredo PH, Zin WA, Guimarães FS. Flutter valve improves respiratory mechanics and sputum production in patients with bronchiectasis. Physiother Res Int 2012;17(1):12-20.

28. Eaton T, Young P, Zeng I, Kolbe J. A randomized evaluation of the acute efficacy, acceptability and tolerability of flutter and active cycle of breathing with and without postural drainage in non-cystic fibrosis bronchiectasis. Chron Respir Dis 2007;4(1):23-30.

29. Eller J, Lapa e Silva JR, Poulter LW, Lode H, Cole PJ. Cells and cytokines in chronic bronchial infection. Ann N Y Acad Sci 1994; 725:331-345

30. Angrill J, Agustí C, De Celis R, Filella X, Rañó A, Elena M, et al. Bronchial inflammation and colonization in patients with clinically stable bronchiectasis. Am J Respir Crit Care Med 2001;164(9):16281632 .
31. Moritz P, Steidle LJM, Felisbino MB, Kleveston T, Pizzichini MMM, Pizzichini E. Determinação do componente inflamatório das doenças das vias aéreas através do escarro induzido: utilização na prática clínica. J Bras Pneumol 2008;34(11):913-921.

32. Barker AF. Bronchiectasis. N Engl J Med 2002;346(18):1383-1393.

33. Pasteur MC, Helliwell SM, Houghton SJ, Webb SC, Foweraker JE, Coulden RA, et al. An investigation into causative factors in patients with bronchiectasis. Am J Respir Crit Care Med 2000;162:12771284.

34. Angrill J, Agustí C, de Celis R, Rañó A, Gonzalez J, Solé T, et al. Bacterial colonisation in patients with bronchiectasis: microbiological pattern and risk factors. Thorax 2002;57(1):15-19.

35. Pasteur MC, Bilton D, Hill AT. British Thoracic Society guideline for non-CF bronchiectasis. Thorax 2010;65(Suppl 1):i1-58.

36. Ergan Arsava B, Cöplü L. Does airway colonization cause systemic inflammation in bronchiectasis? Tuberk Toraks 2011;59(4):340-347.

37. Martínez-García MA, Soler-Cataluña JJ, Perpiñá-Tordera M, RománSánchez P, Soriano J. Factors associated with lung function decline in adult patients with stable non-cystic fibrosis bronchiectasis. Chest 2007;132(5):1565-1572.

38. Loebinger MR, Wells AU, Hansell DM, Chinyanganya N, Devaraj A, Meister M, Wilson R. Mortality in bronchiectasis: a long-term study assessing the factors influencing survival. Eur Respir J 2009; 34(4):843-849

39. Nicolini A, Cardini F, Landucci N, Lanata S, Ferrari-Bravo M, Barlascini $\mathrm{C}$. Effectiveness of treatment with high-frequency chest wall oscillation in patients with bronchiectasis. BMC Pulm Med 2013; 13:21. 